\title{
JUSTIFYING THE DEADLY FORCE RESPONSE
}

\author{
THOMAS A. HONTZ
}

Scottsdale Police Department, Arizona

This article provides an overview of research conducted between May and July 1996. The research was designed to determine how fast an officer can react with an accurate shot after a visual cue. This was contrasted with the speed of typical movements by suspects that would trigger a response with a firearm by a police officer. The results of the research provide empirical evidence to support justified shootings by the police as well as more closely defining when a suspect becomes a deadly force threat.

The use of deadly force is the most serious decision a police officer has to make. Most police officers complete their entire careers without having to make that decision. Those who are faced with the decision are guided by their department's policy and the U.S. Supreme Court case of Tennessee v. Garner (1985). The primary tenet of Tennessee v. Garner states that officers are justified in the use of deadly force to prevent death or serious bodily injury to themselves or a third person. This requirement would seem to be clear. However, because these types of situations usually are very fast moving, and the decision on whether the suspect's actions constitute the likelihood of death or serious bodily injury is a subjective one by the officer, the use of deadly force by the police is generally very controversial. Very rarely does the use of deadly force by the police meet with the approval of all members of the community.

The majority of the uses of deadly force by the police involve the use of firearms. After a police officer shoots a suspect, there usually follows a period of second-guessing and questioning the actions of the police officer. The officer will be investigated by his department. Beyond that, the officer will be judged by the press and the members of the community. Occasionally,

POLICE QUARTERLY Vol. 2 No. 4, December $1999 \quad 462-476$

(C) 2000 Sage Publications, Inc. 
these judgments will be malicious and based on issues other than the facts surrounding the incident.

Generally, the judgments by the public and the press of police use of deadly force are based on misconceptions and misinformation. The public sees guns being shot out of suspects' hands and officers never missing on TV shows and cannot understand why it was not done like that in real life. Often police departments are their own worst enemies because they cannot explain their actions or training policies in a manner these members of the community can understand. These explanations usually consist of the department's policy, the firearms training methods, and how they apply in this particular case.

The department can defend its policy if it is modeled after the Tennessee v. Garner decision. The points of contention with the members of the community are generally the perception of the threat by the officer and the department's firearms training program. The department frequently cannot give explanations to these issues that satisfy the public because they are not research based. Most departments do not design their training around a needs assessment. The training consists of meeting the state standards to keep their officers qualified.

When confronted with the question of why the officer felt the subject was a deadly threat, the department is unable to provide any documented research to back up its explanations. For example, it has generally been accepted within law enforcement circles that a subject with an edged weapon within 21 feet can stab an officer before the officer can react and shoot the suspect. This quasi-standard has been in law enforcement for numerous years, but very few, if any, instructors can provide documentation to support it. When an officer from their department shoots a subject 15 feet away who has a knife, they explain to the public that it is a recognized standard in law enforcement that a subject within 21 feet with a knife is a deadly threat. When they cannot provide documentation to support this claim, the public questions the explanation.

The FBI's (1994) Law Enforcement Officers Killed and Assaulted summary indicates that 75 officers were killed with firearms, including 63 with handguns, in calendar year 1994. After subtracting the officers killed with their own weapons, 57 officers were slain with handguns the suspect probably had concealed on or near him at the time of contact with the police. The 10-year period 1985-1994 indicates that 426 officers were killed with handguns, excluding those taken from the officer and used to kill him. In 1994, 62 officers were shot and killed at a distance of 10 feet or less. During the 
10-year period, 495 officers were shot and killed within a distance of 10 feet. Eighty-seven percent of the officers killed by firearms were killed at a distance of 20 feet or less. Almost $80 \%$ of the officers slain were shot somewhere on the front of their body, indicating they were probably facing their attacker. During that same 10-year period, another 10 officers were killed with knives or other cutting instruments. The profile of the officer killed is male, 36 years of age, with 10 years of police experience.

In 1994, 64,912 police officers were assaulted, 3,168 with firearms, 1,513 with knives or other cutting instruments, and 7,210 with other dangerous weapons. The FBI does not specify the definition of a dangerous weapon, except to differentiate it from personal weapons. It is probably safe to assume that at least some of those would be close-in contact weapons such as sticks, bottles, and tools. These totals are down slightly from the 10-year high in 1992 when 81,252 officers were assaulted, 4,455 with firearms, 2,095 with knives or other cutting instruments, and 8,604 with other dangerous weapons.

During 1994, and also reflected in the 10-year period, a police officer was assaulted or killed with a firearm every 2.6 hours. During this same period, a police officer was assaulted with a knife every 5.49 hours. Every 1.77 hours a police officer was faced with an assault by either a firearm or a knife. This does not even include the assaults with other dangerous weapons. About every 2 hours, a police officer is confronted with an assault that justifies the use of deadly force. This means that about every 2 hours, somewhere in the United States there is a law enforcement agency that may have to deal with the aftermath of a police shooting.

This is the quandary for law enforcement: Thousands of police officers are being assaulted with firearms, knives, and other dangerous weapons each year. Close to a hundred officers each year are dying from these assaults. Yet, when faced with dealing with these threats, which justifiably require the use of the firearm, the police often cannot explain their actions in a manner the community they serve understands. Why don't the police shoot to wound? Why didn't the officer shoot the knife out of the suspect's hand? How could the officer miss at that close distance? Did the officer have to shoot the suspect; he was still several feet away with the knife? To respond to these inquiries with facts developed through research, this project was conceived. The author and Detective Ray Rheingans of the Scottsdale Police Department in Arizona conducted research in the summer of 1996 to provide data to attempt to answer these questions. It was our intent to document 
the firearms abilities of officers in a scientific method when engaging large and small targets (shooting center mass vs. shooting to wound or disarm). This information was contrasted with the time it takes a suspect to make a lethal attack on a police officer, in an attempt to determine if current firearms beliefs and training are adequately preparing the officer for that assault.

Three questions were focused on during this research:

1. When presented with a visual stimulus, how fast can an officer respond with an accurate shot on targets of varying sizes from a gun drawn from a ready position or a holstered position?

2. Does the choice between a single target or two targets with a single-shot stimulus affect the speed at which the officer can respond with an accurate shot?

3. What is the movement time for a suspect to employ a firearm from various carry positions and how fast can the suspect cover ground when wielding a contact weapon (knife or club)?

\section{METHODOLOGY}

The tests for this research were designed to determine how fast a police officer could respond to a visual stimulus with a single accurate shot. Although officers rarely fire only a single shot in a deadly force situation, the purpose of this study was to determine how fast the first accurate shot could be fired. Because each confrontation is unique in the number of shots it takes to end, it would be impossible to measure the amount of time it would require to fire sufficient shots to terminate any given deadly force encounter. However, most firearms experts would agree that an officer could not miss fast enough to survive a gunfight. In other words, it doesn't matter how fast the officer shoots if he doesn't hit what he is shooting at. For that reason, all the testing involved single-shot responses and only hits on the designated targets were used in calculating the results.

In designing the tests, the desired result was to have the tests represent the actions an officer might have to replicate in a deadly force situation in an actual confrontation. Because the primary stimulus that predicates a deadly force (shooting) response is visual, the tests were designed around a visual start signal. Most shot timers, however, use an auditory signal as the start signal. The company PACT Timers was contacted to convert a shooting timer to create a visual rather than an auditory signal. PACT Timers ex- plained how to connect the timer to a light that would illuminate rather than have the timer give an auditory start signal. Two wooden target frames were constructed with a red lightbulb attached to the top of the frame. It was possible 
to control which target was illuminated as the timer began recording elapsed time. The timer maintained a record of each individual's shots until the conclusion of the series of tests, and the information was then entered into a spreadsheet for calculations.

All tests were conducted at a distance of 5 yards. The distance was chosen for two reasons. The first was that research by the FBI indicates that most police shootings occur at a distance of 7 yards or less, with the majority occurring at slightly over 3 yards or less. The second reason for selecting this distance was that the participants in the study did not routinely shoot at this distance. The qualification course they normally shoot has stages at the 3- and 7-yard distances. The selection of an unknown distance eliminates the possibility of the test subjects having developed muscle memory to respond at a known distance. In a street situation, the officers would have to respond to the threat not knowing the actual distance.

The two target frames were set side by side, with 3 feet from inside edge to inside edge of each frame. The test subject was centered between the two targets, 5 yards away. To engage either target, the test subject had to turn less than 15 degrees in either direction. To ensure that each test subject started in the same position, the proper low ready position was discussed with the department's firearms instructors. After the proper low ready position was determined, a board attached horizontally to a tripod was placed so that the muzzle of the gun rested in a square drawn on the board. Each test subject was told to lightly rest the muzzle in the square prior to starting each new repetition.

Originally, four tests were constructed. In Test 1 , an 81/2-by-14-inch canary yellow sheet of paper was centered on the left target frame. The background behind the paper was white. The yellow paper is approximately the size of the "kill zone" on a standard qualification target. Plain paper was used to prevent the test subject from focusing on any one part of the target. Subjects started in the ready position described above. They were told that only the left target would be used. When the light on the frame lit, they were to shoot one round as fast as they could to guarantee a hit anywhere on the yellow sheet of paper. This was repeated a total of eight times, one round per light, each time starting in the low ready position.

Test 2 consisted of using both target frames with the 81/2-by-14-inch yellow paper centered on each. Subjects started in the ready position and were told either target might light up. They were told to shoot one round as fast as they could into the yellow paper on the target that lit. This was repeated a total of eight times. 
Test 3 returned to using only the left target. A 3-by-5-inch canary yellow sheet of paper was placed on the target frame. Subjects were told only the left target would light. Again, they were to put one round into the yellow paper as fast as they could. This was repeated eight times.

In Test 4, both target frames were used with the 3-by-5-inch yellow paper. Subjects were told either target might light. They were to put one round into the yellow paper of the target that was lit. Eight repetitions were completed. Unknown to the subject, on both Tests 2 and 4, the same order of left and right targets was used. This same order was used for all the test subjects. This was to ensure that (a) an equal number of left and right targets were engaged, (b) the subjects could not anticipate which target was going to be used, and (c) there would be consistency for all the subjects.

To avoid subjects' being able to anticipate the light, several controls were used. The PACT timer has a random countdown function. When the start button is activated, it automatically selects a random number of seconds to countdown before initiating the start signal. The operator of the test equipment sat behind the test subject, out of the line of vision, so the test subject was not able to see the operator move. The test subject was wearing heavy hearing protection, which prevented the hearing of the selection switches for the target lights being changed between repetitions.

After testing 31 subjects, a fifth test was added to the process. In the fifth test, the subject started with a holstered firearm. The subject was allowed to use his duty holster. The majority used the department-issued uniformed duty holster. Several detectives used their duty holsters. In all instances, this was a thumb-break holster with a covered trigger guard worn on the belt on the strong side. All holsters were Level 2 security holsters. The left target with the $81 / 2$-by-14-inch paper was used as in Test 1 . When the light lit, the subject drew and fired one round into the yellow paper. The test was repeated a total of eight times.

All test subjects used the same test weapon. The weapon used in the testing was a Glock model 22 (.40 Smith \& Wesson caliber) with Trijicon threedot night sights. It was equipped with the New York trigger. All the test subjects carry the Glock Model 22 as their department-issued duty weapon.

A total of 76 subjects from the Scottsdale Police Department participated in the testing process. Testing was conducted between May 30 and July 3, 1996. Thirty-one subjects completed only the first four tests; the remaining 45 subjects completed all five tests. Test subjects were selected randomly. A roster listing sworn members of the department by serial number was used. Initially, every fourth person on the list was selected to participate in the 
study. However, it was determined that the number of female officers selected in this manner underrepresented the number of female officers on the department. To ensure there were sufficient female officers in the study to make their numbers significant, the remainder of the female officers in the department were asked to participate, although all did not. The total number of male officers in the study was $56(74 \%)$, and the total number of female officers was $20(26 \%)$. This is representative of the male to female officer ratio in the department.

The average age for all participants in the study was 35.3 , and the average years of experience was 10.2. This is almost identical to the FBI (1994) profile of the officers killed in the Law Enforcement Officers Killed and Assaulted summary. The average age for the male officers was 35.8, and for the females, 33.8. The average years of experience was 11.2 for the male officers and 7.6 for the female officers.

For the second portion of the study, to determine the movement time of suspects, a broadcast-quality videocamera with a time generator was used to record various suspect movements. The movements videotaped included a run from a standing position, raising and firing of a gun held by the side of the leg, the draw and fire from a holster on the hip, the draw and fire from an inside-the-pants ("belly") carry, and the draw and fire from a small-of-theback carry. For the holster and inside-the-pants draws, the subjects started with their hands by their sides. For the rear draw, they started with their gun hand on the gun. This was to represent a subject who has been asked for identification but instead of reaching for his wallet, draws a gun concealed in the small of the back. The subjects were told to come up on target as quickly as possible and squeeze off a shot. They were not required to hit a target or aim at a target. Their movements were designed to replicate a suspect's actions. They were to shoot as quickly as possible without the constraints of departmental policy or worrying about civil liability for missing the intended target and hitting an innocent bystander. For both the suspect and officer tests, the timing was concluded at the end of one shot to avoid the multitude of possible permutations of hits, misses, effects of the rounds, and the will to win of the subjects involved. A total of 22 subjects were timed, doing the run two times each and each of the draws five times. Using the time generator on the tape, the time to complete each movement could be measured. The time was measured from the first movement of the test subject to the completion of the act (firing the weapon or completing the run). The run was one continuous run with times being recorded at the 15-, 20-, 25-, and 30-foot lines. 
TABLE 1. Average Time for Officers to Fire One Accurate Shot (in seconds)

\begin{tabular}{lcccc}
\hline \hline $\begin{array}{l}\text { One Large } \\
\text { Target }\end{array}$ & $\begin{array}{c}\text { Two Large } \\
\text { Targets }\end{array}$ & $\begin{array}{c}\text { One Small } \\
\text { Target }\end{array}$ & $\begin{array}{c}\text { Two Small } \\
\text { Targets }\end{array}$ & $\begin{array}{c}\text { One Large Target, } \\
\text { Draw From Holster }\end{array}$ \\
\hline 1.15 & 1.11 & 1.56 & 1.58 & 1.90 \\
\hline
\end{tabular}

TABLE 2. Hit Ratio for All Tests (in percentages)

\begin{tabular}{lcccc}
$\begin{array}{l}\text { One Large } \\
\text { Target }\end{array}$ & $\begin{array}{c}\text { Two Large } \\
\text { Targets }\end{array}$ & $\begin{array}{c}\text { One Small } \\
\text { Target }\end{array}$ & $\begin{array}{c}\text { Two Small } \\
\text { Targets }\end{array}$ & $\begin{array}{c}\text { One Large Target, } \\
\text { Draw From Holster }\end{array}$ \\
\hline 93 & 95 & 75 & 74 & 94 \\
\hline
\end{tabular}

\section{RESULTS}

The results of the tests are shown in Table 1. The number of hits and misses was also recorded and are reflected in Table 2.

Statistical analysis was conducted on the results of the tests to determine if there was any significance between the results and if there was any particular factor that influenced better or worse performance. There was a significant difference between Tests 1 and 2 but no significant difference between Tests 3 and 4 . The only differences in the actual tests were the size of the targets, so it was believed that Tests 1 and 2 and Tests 3 and 4 should mirror each other. If it was a significant difference in time to shoot one large target and two large targets, then it should also hold true for one small target and two small targets. It is hypothesized that during Test 1 the officers were firing "cold," without any warm up. By Test 2 they had fired eight shots and had a chance to practice, hence the faster times for Test 2 even though there was slightly more physical motion involved (slight rotation left or right to engage the appropriate target). By Tests 3 and 4, the officers were warmed up and there was no significant difference in times between the tests. There is no empirical evidence to support this interpretation, but it is based on observations of the test group.

The data were then arranged to isolate different characteristics of the test group to determine if there was any particular trait that affected the results. The only trait that showed any significance across all five tests was the area of specialized training. 
TABLE 3. Average Time for Suspects to Complete Various Movements (in seconds)

\begin{tabular}{ll}
\hline \hline Draw from holster & 1.19 \\
Front draw & 1.09 \\
Rear draw & 0.78 \\
Raise and fire & 0.59 \\
Run 15 feet & 1.28 \\
Run 20 feet & 1.57 \\
Run 25 feet & 1.79 \\
Run 30 feet & 2.06 \\
\hline
\end{tabular}

The second half of this project involved the measuring of the movement time of various suspect movements. The movement time average test results for the suspect test group are shown in Table 3.

No statistical testing was conducted between the various suspect tests. The purpose of these tests was to provide data to compare with the officer results. It did not matter whether age, sex, or training affected the results. With the exception of sex, and to some extent age, the officer facing the suspect will not be able to visually ascertain whether the suspect will be the rule or the exception to the rule.

\section{DISCUSSION}

The results of this study have some strong implications for the teaching of firearms to law enforcement personnel. The general belief is that a police officer is not justified in shooting an armed subject until the subject's weapon begins to move to be pointed at the officer or another person. However, in many situations, the officer is going to lose if he waits that long to engage the suspect. Compare, for instance, the officer's time for shooting at one large target from a ready position (1.15 seconds) with the offender's movement time for an inside-the-pants (belly) draw (1.09 seconds). This means that an officer could be covering a subject in a ready position, watching the subject's hands, and the subject could draw his weapon and fire a round before the officer could shoot. Even though the suspect wins by a very small margin, in this event, ties for the police are losses. The explanation for this occurrence requires the examination of response, reaction, and movement time.

Reaction time is a mental process. It generally can be broken down into three or four components. The pressure point control tactics (PPCT) model designed by Bruce Siddle (1982) uses four components. PPCT Management 
Systems, Inc. is a research-based use-of-force training company that has trained instructors throughout the world. In the PPCT model, the first component of reaction time is perception. In police work, this is primarily going to be through the visual system. But in some manner, the officer perceives a threat or other stimulus that will require him to act.

The second stage is analyze and evaluate. In this stage, the officer is making judgments on what he is perceiving and how it affects him. For example, an officer walks up to a pickup truck. Lying on the dashboard is a pistol. The analysis tells him that it is a pistol, it appears to be real, has a magazine in it, and is cocked. The evaluation deals with the relevance of the pistol to the officer. If the truck is unoccupied with no one around it, the relevance is significantly different than if there is a subject in the truck, wearing gang attire, within arm's reach of the pistol.

The next stage is the formulation of a plan. This will depend on the officer's training and life experiences. If the officer has not had training to deal with the particular threat he is facing he will attempt to create a plan by pulling pieces of information from training and experience that have similarities to some part of the threat.

The final stage is initiating motor action. This involves the brain sending messages to the appropriate muscles to carry out the plan.

Movement time is physical. It is the actual movements to carry out the plan that was devised in the reaction time phase. The actual length of the movement time will depend on the complexity of the movements involved in the plan.

Response time is the combination of reaction time and movement time. Depending on the circumstances, response time may be fractions of a second, or it may be several seconds, or even minutes, in length.

Graphically, the response time continuum appears in Figure 1. In reality, the reaction time and movement time sections are not equal in length as depicted in the figure. Depending on the threat stimulus and the plan devised to deal with it, reaction time may be shorter or longer than movement time. The important aspect is that reaction time, being a mental process, is not visible. The officer who is in a ready position with gun drawn covering a suspect, who has a gun in his waistband, can't see the suspect's mental process. The suspect is going through the stages of reaction time, but the officer is waiting for him to move to determine the threat. By the time the suspect moves, the officer must now go through the stages of reaction time before he can move against the threat. It becomes a question of the officer's response time against the suspect's movement time. 


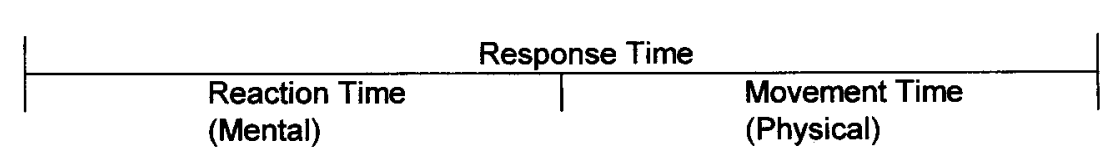

FIGURE 1: Response Time Continuum

Being aware of the response time versus movement time discrepancy is a beginning. But being aware is not enough if it does not help the officer deal with the problem. The FBI statistics indicate that, on average, every 2 hours, somewhere in the United States, a law enforcement officer is faced with a deadly force encounter. The officer is probably going to be a victim of the response time continuum. This awareness should help the officer recognize more clearly when the suspect is truly a threat.

This study indicated that the test subjects with specialized firearms training had faster response times in the tests. However, the study could not clearly delineate whether more proficiency (more practice) or higher skill level (instructor background) or both caused the better response times. Nonetheless, these faster times are, for all intents and purposes, meaningless. It is apparent that even though the subjects with specialized training had faster times, they are still at a disadvantage pitted against the suspect's movement time.

Another important factor to consider is that all the officers in this study knew they were going to shoot. They did not have to identify whether they were facing a deadly force encounter, they did not have to mentally review departmental policy or their own moral views on killing prior to shooting. In a real-life scenario, all those components would be part of the reaction time mode. It is believed that would only serve to lengthen the officer's response time and that the test times recorded here are probably best-case times, recorded in a nonstressful, known environment. Conversely, the suspect movement time portion would be unaffected by these considerations. In a real-life scenario, the suspect may take longer to decide what he wants to do (reaction time) but the officer will be unaware of the thought process. Once the suspect has decided what he wants to do, the movement time is probably consistent with those times determined in this study.

This study also modifies the Tueller 21-foot rule dealing with subjects armed with knives or other contact weapons. Dennis Tueller attempted to give some better guidelines to police officers to determine when a subject with a knife or contact weapon is close enough to be a threat with that 
weapon. Tueller timed officers in a firearms class while they drew their weapons. Based on his findings, Tueller decided that if a subject was 21 feet or closer, he was a deadly threat if he was armed with a knife and the officer's gun was still in the holster. The results of this study show that $21 \mathrm{feet}$ is too conservative a distance. This means if an officer has her weapon out at the ready position and aims for body mass (large target), the officer should be able to get one round off before the suspect can cover 15 feet. However, if the officer attempts a precise shot (small target) the suspect will be able to cover 20 feet. If the officer's gun is in the holster and she draws and fires to body mass, the suspect will be able to cover almost 30 feet.

Again, it is important to emphasize that these are probably best-case times by the officers. If the weapon is not apparent, the officer is unclear in her mind if the suspect is really a threat, or if the officer is surprised by the attack, the response times will probably be longer. The other important factor is that one single shot will not necessarily terminate the attack. Even a fatal wound will not drop an attacker in his tracks (especially from a handgun), and the momentum of the attacker may still carry the knife into the officer.

Finally, the third contribution of this study is to provide some research data to answer the question citizens and the media often pose, why didn't the officer shoot the gun or knife from the suspect's hand? Fitt's law is a motor learning principle that posits a speed/accuracy trade-off. If the physical skill requires a higher degree of accuracy, that accuracy will cause a loss of speed compared with the same action requiring less accuracy. When the target area was changed from the torso-size $8 \frac{1}{2} 2$-by-14-inch paper to the hand-size 3-by-5-inch paper, response times increased by almost a half second. That half second is extremely important when the officer is already trying to catch the suspect on the response time continuum. Along with the increase in response time with the smaller target, there was a significant loss in accuracy. Considering that the officers were only 5 yards away in a nonstressful (non-life threatening) environment, shooting at a target that was not moving, they still missed one out of four times. Even shooting at the large targets, the officers missed about $5 \%$ of the time. Each of those misses in an actual field situation is the possibility of an innocent bystander being hit. Those hit ratios are only going to get worse as the stress level increases, the distances get longer, and the target moves. Even the subjects with specialized firearms training did not hit what they were shooting at every time. They too had a substantial increase in misses when they went from the large to the small targets. 


\section{CONCLUSIONS}

The use of deadly force by a police officer is always marked by controversy. No matter how justified the shooting appears, there will always be individuals or groups ready to attack the officer's actions. We are a society that has been trained by the multitude of police action shows on TV. In those shows, the police never miss, the issues are always clear, and the viewer knows everything that has led up to the shooting. This is not so in the real world. When reality conflicts with the television world, members of the public become frustrated. They believe the agency is hiding something. Or they are driven for the deep pockets of the agency, hoping to recover something in the agency's desire to avoid adverse publicity or the cost of defending civil litigation.

It is hoped that this research will help accomplish two things. First, administrators and legal advisers have research to help explain and defend officers' actions. They can explain, in concrete, verifiable ways, why officers are taught to shoot for the largest target and how the officer or another person was in mortal danger. No longer do they need to say only, the officer was in fear for his life. They can explain how he was in danger and show why his actions were reasonable. The public can be educated that shooting to wound, or to disable the weapon hand, actually puts them in greater risk of being hurt by shots that do not hit the intended target. In addition, the time taken to make these precise shots further endangers the officer and the citizen.

Administrators must also understand the officer's actions from the officer's perspective. It has been a long-held belief that the suspect does not pose a threat until he begins to move the weapon. The results of this study show that waiting until the suspect begins to move the gun may be fatal to the officer. This does not give officers carte blanche to shoot anyone with a gun in his hand. But faced with an uncooperative armed subject, where the officer has little or no cover, waiting for the subject to make that movement endangers both the officer and innocent bystanders. Administrators should not be quick to judge police-involved shootings until all the facts are in, no matter how it initially looks.

It is also hoped that this research will stimulate changes in training. Use-of-force instructors in general, and firearms instructors specifically, need to discuss the aspects of response, movement, and reaction time with their students. Once the students understand these concepts, it should be easier for them to recognize threat potential and react tactically to it. Knowing the potential danger of being on the wrong side of the response time continuum should influence better tactics to control the situation. Better tactics 
include more efficient use of cover, proper positioning of officers relative to suspects, and better use of personnel. Understanding how, and at what distances, a subject can be considered a threat should allow officers to plan responses to calls more effectively. If the situation requires the use of deadly force, the officer should have a clear understanding of why and how the subject was a threat, which will speed decision making. This understanding will also help with the articulation of the justification for deadly force. This study should help to define when the suspect becomes a deadly force threat. Armed with that knowledge prior to being placed into the situation, the officer should be able to recognize the threat and deal appropriately with it, and not have to analyze it.

There is probably nothing that causes more controversy in the community than the use of deadly force by the police. The public wants answers that are as clear-cut as those they see on TV. The information contained in this report should make it easier to explain to those we serve the reasons behind our actions.

\section{SUGGESTED READINGS}

Adams, R. J., McTernan, T. M., \& Remsburg, C. (1980). Street survival: Tactics for armed encounters. Evanston, IL: Calibre.

Ayoob, M. F. (1980). In the gravest extreme. Concord, NH: Police Bookshelf.

Ayoob, M. F. (1984). Stressfire. Concord, NH: Police Bookshelf.

Barber, D. L. (1986). Law enforcement firearms training. Garden Grove, CA: D. L. Ventures. Dees, C. (Ed.). (1994). The best of Police Marksman. Montgomery, AL: Police Marksman Association.

Farnum, J. (1986). The street smart gun book. Concord, NH: Police Bookshelf.

Hillmann, M. R. (1995, Spring). Physical lag times and their impact on the use of deadly force. The Tactical Edge, pp. 28-30.

Magill, R. A. (1980). Motor learning: Concepts and applications. Dubuque, IA: William C. Brown.

Schmidt, R. A. (1988). Motor control and learning. Champaign, IL: Human Kinetics. Schmidt, R. A. (1991). Motor learning and performance. Champaign, IL: Human Kinetics. Shaw, J. (1982). You can't miss. Memphis, TN: Shaw-Bane.

Siddle, B. K. (1995). Sharpening the warrior's edge. Millstadt, IL: PPCT.

\section{REFERENCES}

Federal Bureau of Investigation. (1994). Law enforcement officers killed and assaulted [Uniform Crime Reports]. Washington, DC: Author. 
Siddle, B. K. (1982). Defensive tactics instructor manual by Bruce Siddle. Millstadt, IL: PPCT.

Tennessee v. Garner, 105 S. Ct. 1694 (1985).

Thomas A. Hontz is a 22-year veteran of the Scottsdale Police Department, Arizona. He currently supervises the Special Assignments Unit, the full-time component of the department's SWAT team. Sergeant Hontz is the department's use-of-force expert and oversees the use-of-force training for the department. He is a staff instructor for PPCT Management Systems, Inc., an international use-of-force training company, and serves on that organization's research committee. He has taught use-of-force topics nationally and internationally. 